OPEN ACCESS

Edited by:

Dan J. Bower,

University of Bern, Switzerland

Reviewed by:

Zhicheng Jing,

Southern University of Science and

Technology, China

Alexander F. Goncharov,

Carnegie Institution for Science (CIS),

United States

*Correspondence:

Chrystèle Sanloup

chrystele.sanloup@

sorbonne-universite.fr

Specialty section:

This article was submitted to

Earth and Planetary Materials,

a section of the journal

Frontiers in Earth Science

Received: 15 January 2019

Accepted: 19 March 2019

Published: 10 April 2019

Citation:

Sanloup C, Hudspeth JM, Afonina V,

Cochain B, Konôpková Z, Lelong G,

Cormier L and Cavallari C (2019)

Polymerized 4-Fold Coordinated

Carbonate Melts in the Deep Mantle.

Front. Earth Sci. 7:72.

doi: 10.3389/feart.2019.00072

\section{Polymerized 4-Fold Coordinated Carbonate Melts in the Deep Mantle}

\author{
Chrystèle Sanloup ${ }^{1 *}$, Jessica M. Hudspeth ${ }^{2}$, Veronika Afonina ${ }^{3}$, Benjamin Cochain ${ }^{2}$, \\ Zuzana Konôpková ${ }^{4}$, Gérald Lelong ${ }^{1}$, Laurent Cormier $^{1}$ and Chiara Cavallari ${ }^{5}$ \\ 'Muséum National d'Histoire Naturelle, UMR CNRS 7590, IRD, Institut de Minéralogie, de Physique des Matériaux et de \\ Cosmochimie, IMPMC, Sorbonne Université, Paris, France, ${ }^{2}$ Institut des Sciences de la Terre de Paris, Sorbonne Université, \\ CNRS, Paris, France, ${ }^{3}$ SUPA, Centre for Science at Extreme Conditions and School of Physics and Astronomy, University of \\ Edinburgh, Edinburgh, United Kingdom, ${ }^{4}$ DESY Photon Science, Hamburg, Germany, ${ }^{5}$ European Synchrotron Radiation \\ Facility, ESRF, Grenoble, France
}

Our understanding of the deep carbon cycle has witnessed amazing advances in the last decade, including the discovery of tetrahedrally coordinated high pressure $(P)$ carbonate phases. However, little is known about the physical properties of their molten counterpart at moderate depths, while their properties at lower mantle conditions remain unexplored. Here, we report the structure and density of $\mathrm{FeCO}_{3}$ melts and glasses from 44 to $110 \mathrm{GPa}$ by means of in situ x-ray synchrotron diffraction, and ex situ Raman and $\mathrm{x}$-ray Raman spectroscopies. Carbon is fully transformed to 4-fold coordination, a bond change recoverable at ambient $P$. While low $P$ melts react with silica, resulting in the formation of silico-carbonate glasses, high $P$ melts are not contaminated but still quench as glasses. Carbonate melts are therefore polymerized, highly viscous and poorly reacting with silicates in the lower mantle, in stark opposition with their low $P$ properties.

Keywords: carbonate melts, high pressure, $x$-ray diffraction, Raman, $x$-ray Raman, polymerization, deep mantle

\section{INTRODUCTION}

Although the lower mantle is mostly a reducing environment with the presence of reduced Fe (Frost et al., 2004; Smith et al., 2016), significant amount of subducted carbonates are estimated to be preserved (Litasov and Shatskiy, 2018). Transition to 4 -fold carbon was first predicted for crystalline $\mathrm{CaCO}_{3}$ (Oganov et al., 2006; Arapan et al., 2007). This transition strongly depends on the carbonate composition, occurring for $\mathrm{CaCO}_{3}$ above $105 \mathrm{GPa}$ (Lobanov et al., 2017), $80 \mathrm{GPa}$ for $\mathrm{MgCO}_{3}$ (Oganov et al., 2008; Boulard et al., 2011), and $50 \mathrm{GPa}$ for $\mathrm{FeCO}_{3}$ (Liu et al., 2015), while intermediate $\mathrm{CaCO}_{3}-\mathrm{MgCO}_{3}-\mathrm{FeCO}_{3}$ compositions form a single tetrahedral carbonate phase (Merlini et al., 2017) unlike silicates. This transition induces polymerization such as sheets or 3-membered rings for $\mathrm{MgCO}_{3}$ (Oganov et al., 2008), and chains for $\mathrm{CaCO}_{3}$ (Oganov et al., 2006). In contrast, our knowledge of carbonate melts structure at depth is scarce and limited to upper mantle pressures. The melting curves of $\mathrm{CaCO}_{3}, \mathrm{Na}_{2} \mathrm{CO}_{3}$, and $\mathrm{FeCO}_{3}$ have been measured over most of the upper mantle regime (Kang et al., 2015; Li et al., 2017), and viscosity measurements up to 6 GPa span several compositions $\left[\mathrm{K}_{2} \mathrm{Ca}\left(\mathrm{CO}_{3}\right)_{2}\right.$ and $\mathrm{K}_{2} \mathrm{Mg}\left(\mathrm{CO}_{3}\right)_{2}$ by (Dobson et al., 1996), $\mathrm{CaCO}_{3}$ and natural dolomite by (Kono et al., 2014), $\mathrm{Na}_{2} \mathrm{CO}_{3}$ by (Stagno, 2018)]. Structural data instead have only been collected on molten $\mathrm{CaCO}_{3}$ below $10 \mathrm{GPa}$ (Hudspeth et al., 2018) while theoretical investigations of the properties of carbonate melts cover a larger $P$-range but are also limited to the carbon 3-fold stability field (Vuilleumier et al., 2014; Zhang and Liu , 2015; Du et al., 2018; Desmaele et al., 2019). One main question is therefore how this 3 to 4 -fold transition translates in the molten state, and what are the consequences on the physical and chemical properties of carbonate melts? Of particular interest is the mobility and reactivity of carbonate melts in the lower 
mantle, knowing that these properties underpin the key role played by carbonate melts in mantle geodynamics through lubrication of plate tectonics, cratonic roots (Foley, 2008) and ascending plumes (Litasov et al., 2013).

The role of $\mathrm{Fe}$ in the deep carbon cycle is emphasized by the predominance of Fe-rich ferropericlase in diamond inclusions from the lower mantle (Kaminsky, 2012). The lowest transition $P$ from 3 to 4 -fold $\mathrm{C}$ in $\mathrm{FeCO}_{3}$ amongst carbonates justifies its choice as the first composition to investigate. Not only this transition occurs at less challenging experimental conditions, but it might be driven by Fe high spin to low spin transition at $40.4 \mathrm{GPa}$ (Weis et al., 2017), a consequence of which being the large enrichment in $\mathrm{Fe}$ of $(\mathrm{Mg}, \mathrm{Fe})$ carbonates coexisting with bridgmanite to almost pure $\mathrm{FeCO}_{3}$ (Lobanov et al., 2015). Besides, high Fe concentration stabilizes $(\mathrm{Ca}, \mathrm{Mg}, \mathrm{Fe})^{\mathrm{IV}} \mathrm{CO}_{3}$ with respect to single cation 3-fold carbonates at mid mantle conditions (30-50 GPa) (Solomatova and Asimow, 2018). Formation of Fe-carbonates in the lower mantle might also result from carbonation of Fe-oxides $[(\mathrm{Mg}, \mathrm{Fe}) \mathrm{O}, \mathrm{FeOOH}]$ with $\mathrm{CO}_{2}$ (Boulard et al., 2018, 2012). Last but not least, $\mathrm{FeCO}_{3}$ is a technical choice as it can be laser heated, which is required to reach lower mantle conditions without the need for additional laser coupler.

\section{MATERIALS AND METHODS}

\subsection{Materials and Chemical Analyses}

The starting natural crystalline siderite sample (mineralogical collection at Sorbonne Université) was loaded in the sample chamber laser-drilled in a rhenium gasket as $20 \mu \mathrm{m}$-thick platelet between two equally thick platelets of compressed $\mathrm{SiO}_{2}$ powder. The $\mathrm{SiO}_{2}$ platelets act as thermal insulators and $P$-transmitting medium. Only one sample was used per $P$ point (Figure 1) to avoid repeated laser-heatings, and preserve the chemical integrity of the sample. Six samples could be recovered after the experiments, embedded in epoxy and polished for analysis. Samples 8, 9, and 15 were carbon-coated for SEM imaging (Figure 2), samples 8 and 15 were then repolished and goldcoated along with samples 13,14 , and 20 for electron microprobe analysis using a CAMECA SX-FIVE analyzer (EMPA) at the Camparis center of Sorbonne Université (Table 1), using the following operating conditions: $15 \mathrm{keV}, 10 \mathrm{nA}$. We used a defocused beam size of $10 \mu \mathrm{m}$ to get an average composition at the laser-heated spot.

\section{2. $\boldsymbol{P}$-T Conditions}

We used diamond-anvil cells and a double-sided infra-red laser focussed down to $20 \mu \mathrm{m}$ to generate high $T$ and $P$. For each $P$ point, targeted power was increased in $2 \mathrm{~W}$ increments from 20 to $50 \mathrm{~W}$ of power on each laser depending on $P$ until complete melting of the sample. Melting was identified by disappearance of diffraction peaks apart from $\mathrm{SiO}_{2}$ peaks, and by the appearance of diffuse scattering. As we used the off-axis heating system to avoid using carbon mirrors that would add to the x-ray background signal and compromise processing of the scattered signal, $T$ could not be measured by pyrometric techniques. $\mathrm{FeCO}_{3}$ melting curve has only been measured up to $20 \mathrm{GPa}$ (Kang et al., 2015), where it

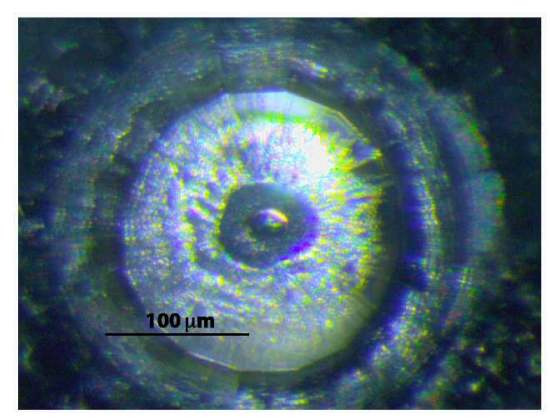

FIGURE 1 | Microphotograph of the sample after laser heating at $110 \mathrm{GPa}$. Single shot laser heating resulted in the formation of a quasi-spherical pure carbonate glass that was removed from the gasket for EPMA and/or SEM analyses.

reaches $1,865 \mathrm{~K}$. The stishovite to $\mathrm{CaCl}_{2} \mathrm{SiO}_{2}$ transition has been investigated up to $90 \mathrm{GPa}$ (Fischer et al., 2018), this constrains $T$ to a maximum of $2,300 \mathrm{~K}$ at $79 \mathrm{GPa}$ and $2,500 \mathrm{~K}$ at $83 \mathrm{GPa}$ as $\mathrm{CaCl}_{2}$ is the observed $\mathrm{SiO}_{2}$ structure for the three highest $P$ runs, while stishovite is observed below. We therefore consider that $\mathrm{x}$-ray diffraction patterns were collected on molten $\mathrm{FeCO}_{3}$ within the $2,000 \mathrm{~K}-2,500 \mathrm{~K}$ interval except for the highest $P$ point that is only constrained to below $3,500 \mathrm{~K}$ from extrapolation of the stishovite- $\mathrm{CaCl}_{2}$ Clapeyron slope (Fischer et al., 2018). $P$ is measured at room $T$ using fluorescence of a ruby sphere added in the sample chamber (Mao et al., 1986) and $\mathrm{SiO}_{2}$ equations of state (Andrault et al., 1998; Nishihara et al., 2005) for quenched samples, and using only $\mathrm{SiO}_{2}$ equations of state for molten samples with error bars on $P$ including the effect of a 2,000 $\mathrm{K}-2,500 \mathrm{~K} T$-range, and up to $3,500 \mathrm{~K}$ for the $110 \mathrm{GPa}$ data point.

\subsection{X-ray Diffraction Methods}

We collected in situ high $P$ - $T$ x-ray diffraction data in laserheated diamond anvil cells at the extreme conditions beamline P02.2 at the PETRAIII synchrotron. We used symmetric diamond-anvil cells equipped with $70^{\circ}$ opening Boehler-Almax seats in order to access a wider $q$-range up to $10 \AA^{-1}$, and reduce the diamond Compton contribution as Boehler-Almax anvils are only $1.5 \mathrm{~mm}$ thick. The $\mathrm{x}$-ray monochromatic beam $(42.7 \mathrm{keV})$ was focussed down to a size of $4 \times 6 \mu \mathrm{m}^{2}$, allowing high spatial resolution in direct space. To limit iron migration away from the laser heating spot due to Soret effect, the laser shutters were opened only once the targeted power was reached, and held open for $10 \mathrm{~s}$ during which $10 \mathrm{x}$-ray diffraction patterns of $1 \mathrm{~s}$ acquisition time were recorded on a Perkin-Elmer 2-D detector. 2-D patterns were integrated using the Fit2D software (Hammersley et al., 1996). In order to isolate the scattered intensity from the molten $\mathrm{FeCO}_{3}$ only, each sample was removed from the gasket, and the gasket put back in place to collect $\mathrm{x}$ ray data on the empty cell. Obtained patterns were then scaled vertically to match the baseline of $\mathrm{x}$-ray patterns collected on the starting crystalline sample under $P$ (Sanloup and de Grouchy, 2018). This last step ensures that any $P$ effect on the background is corrected for. Amongst eight successful runs (Table 1) for 


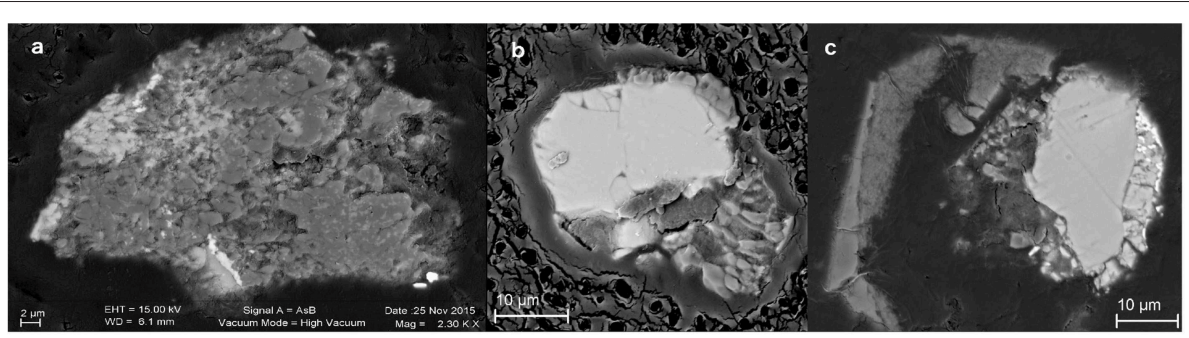

FIGURE 2 | SEM images of recovered samples. Low $P$ sample 8 (a) shows pervasive contamination of carbonate sample with $\mathrm{SiO}_{2} P$-transmitting medium. High $P$ samples 9 (b) and 15 (c) show that chemical integrity of carbonate melt (homogeneous light gray zone) was preserved.

TABLE 1 | Run conditions, quenched products and their chemical composition in wt\% obtained from EMPA. One standard deviations are given in parentheses. Starting natural siderite sample also contained $<0.1 \mathrm{wt} \% \mathrm{CaO}$ and $\mathrm{MnO}$.

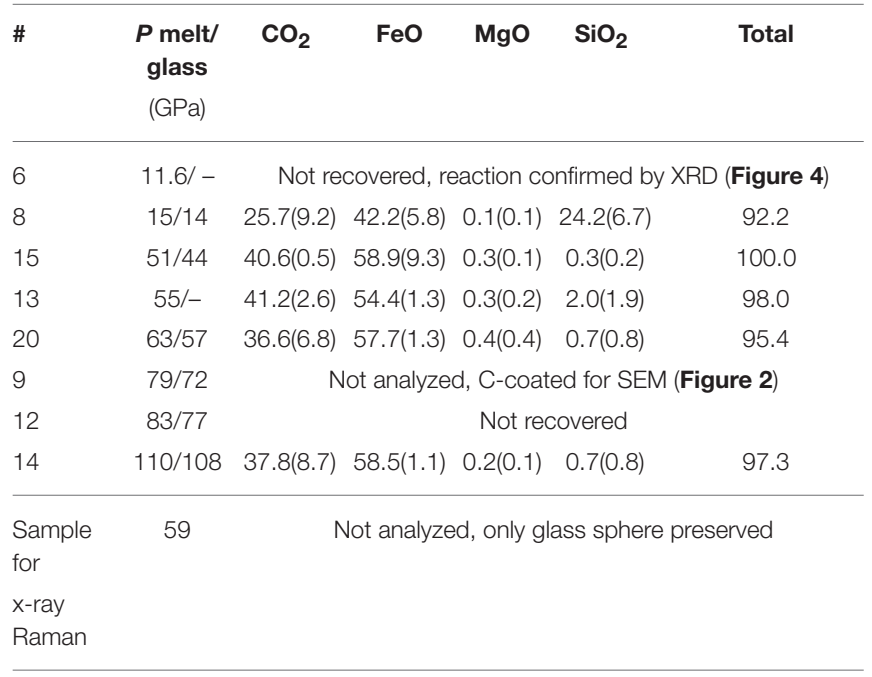

which full melting was observed, intensity from molten $\mathrm{FeCO}_{3}$ could only be processed for the highest $P$ run for which the sample vs. $\mathrm{SiO}_{2}$ platelets thickness ratio was slightly higher, the scattered intensity being too weak for the lower $P$ points. All glass patterns could be processed. The $\mathrm{x}$-ray diffracted intensity data are converted into the structure factor, $S(q)$ (Figures 3A, 4), using the Ashcroft-Langreth formalism. The radial distribution function $g(r)$ (Figure 3B), that describes ion-ion contributions in real space, is obtained by Fourier transforming of $S(q)$,

$$
g(r)=\frac{1}{2 \pi^{2} r n} \int_{0}^{\infty} q S(q) \sin (q r) d q
$$

where $n=\frac{\rho \mathcal{N}_{A}}{M}, \mathcal{N}_{A}$ is the Avogadro number, $M$ the mean atomic molar mass, and $\rho$ the density.

\subsection{Density Measurements}

The method to derive density from x-ray diffraction data on melts compressed in diamond-anvil cell experiments (Eggert et al., 2002; Sanloup et al., 2013) consists in minimizing the oscillations in $g(r)$ where there should not be any signal, i.e., below the minimum interatomic distance $(r<0.95 \AA$ here). This method requires that the background, essentially the Compton signal from the diamond anvils that dominates the total diffracted intensity, is perfectly subtracted.

As the $\mathrm{C}-\mathrm{O}$ contribution is distinct on $g(r)$ of quenched glasses up to $83 \mathrm{GPa}$, we also ran consistency checks by fixing the $\mathrm{C}-\mathrm{O}$ coordination number to 4 as indicated by x-ray Raman spectra ( $c f$ Results section), and simulating the $\mathrm{C}-\mathrm{O}$ contribution using the obtained density values against a gaussian with the following equation:

$$
g(r)=\frac{c_{C} c_{O} K_{C} K_{O}}{Z_{t o t}^{2} n S_{\infty}} \frac{A}{\sigma \sqrt{2 \pi}} \exp \left(-\frac{(r-d)^{2}}{2 \sigma^{2}}\right)
$$

where $c_{C}$ and $c_{O}$ are the atomic proportions of carbon and oxygen, $K_{C}$ and $K_{O}$ are defined as the average effective atomic number over the experimental $q$-range (Eggert et al., 2002) and calculated using form factors from Hajdu (1972).

$$
S_{\infty}=\frac{\Sigma_{p} K_{p}^{2}}{Z_{t o t}^{2}}
$$

and

$$
A=\frac{C N}{\int \frac{4 \pi r^{2}}{\sigma \sqrt{2 \pi}} \exp \left(\frac{-(r-d)^{2}}{2 \sigma^{2}}\right) d r}
$$

with $K_{p}$, the effective atomic number (Eggert et al., 2002), $Z_{t o t}$ the total atomic number of the compositional unit (e.g., $\mathrm{FeCO}_{3}$ ), $\mathrm{CN}$ the $\mathrm{C}-\mathrm{O}$ coordination number fixed to $4, d$ the $\mathrm{C}-\mathrm{O}$ inter-atomic distance, and $\sigma$ a parameter depending on structural disorder, $\sigma=k \sqrt{d}$ where $k$ is an adjustable parameter (Hosemann and Bagchi, 1962) with a value of 0.11 here. The C-O contribution to $g(r)$ thus calculated adequately fits the experimental ion-ion contribution (dashed lines on Figure $\mathbf{2 b}$ ), hence comforting the obtained density values.

\subsection{X-ray Raman and Raman Methods}

Raman and x-ray Raman spectra were collected at ambient conditions on glassy $\mathrm{FeCO}_{3}$ recovered from x-ray diffraction experiments and from additional laser-heated diamond anvil cell synthesis, respectively.

$\mathrm{X}$-ray Raman data were collected at an incident energy of $9.7 \mathrm{keV}$ at the C K-edge on beamline ID20 of the European Synchrotron Radiation Facility (ESRF), beamsize was $15 \times$ 

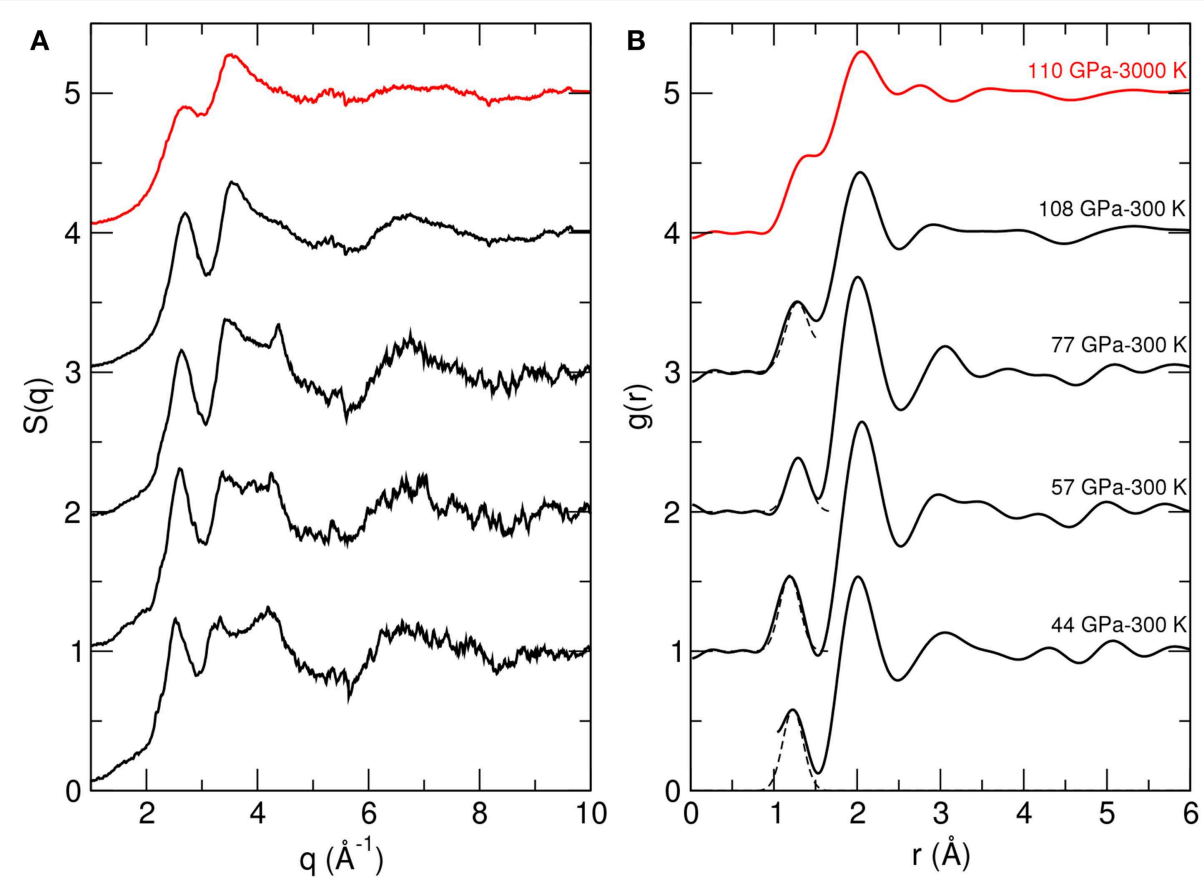

FIGURE 3 | Structure of non-crystalline $\mathrm{FeCO}_{3}$ at high pressures. (A) Structure factor, $S(q)$, for all quenched glasses (black) and the highest $P$ melt (red). (B) Corresponding radial distribution functions, $g(r)$. Dashed lines are fits to the C-O contribution at 1.2-1.3 $\AA$ where there is no overlap with farther contributions.

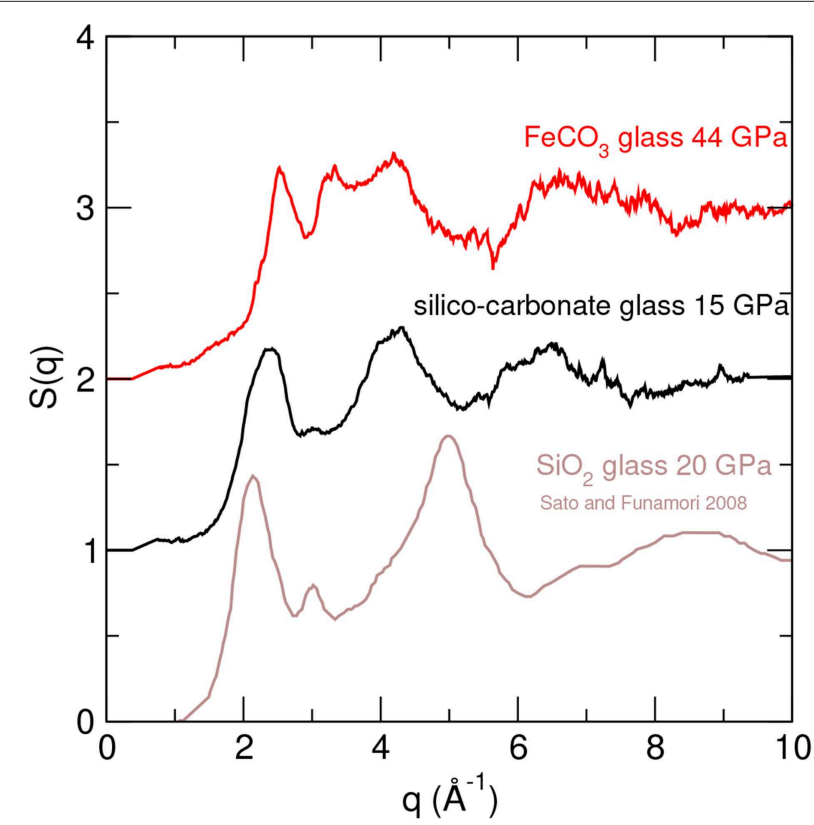

FIGURE 4 | Structure factor, $S(q)$, for low $P$ reacted $\mathrm{FeCO}_{3}+\mathrm{SiO}_{2}$ glass (black), compared to $\mathrm{SiO}_{2}$ glass at $20 \mathrm{GPa}$ (Sato and Funamori, 2008) (brown) and $\mathrm{FeCO}_{3}$ glass at $44 \mathrm{GPa}$ (red). Low $P$ sample 8 (15 GPa) shows intermediate structure between $\mathrm{SiO}_{2}$ glass and high $P \mathrm{FeCO}_{3}$ glasses.

$15 \mu \mathrm{m}^{2}$. The large-solid-angle $\mathrm{x}$-ray scattering spectrometer (Huotari et al., 2017) was set up with $24 \mathrm{Si}(660)$ analyzer crystals for an average momentum transfer of $7.3 \pm 0.2 \AA^{-1}$ and an overall energy resolution of $0.7 \mathrm{eV}$. All experimental data were analyzed using the XRStools software package (Sahle et al., 2015). The integrated intensity of each spectrum was normalized over a $35 \mathrm{eV}$ energy range. Glassy $\mathrm{FeCO}_{3}$ spheres had been previously synthesized at $59 \mathrm{GPa}$ using the same P02.2 laser heating system in PetraIII as for x-ray diffraction experiments. $\mathrm{LiF}$ was used instead of $\mathrm{SiO}_{2}$ as a $P$-transmitting medium to avoid any contamination of the $\mathrm{x}$-ray Raman signal by oxygen from $\mathrm{SiO}_{2}$ as measurements at the $\mathrm{O}$ K-edge were initially planned but signal was to weak for data to be processed. Despite its higher melting curve than siderite (Boehler et al., 1997), LiF salt could not be used for the x-ray diffraction experiments due to its continuous powder diffracted signal that prevents a qualitative analysis of the diffuse scattering signal from molten $\mathrm{FeCO}_{3}$.

Raman spectra were collected on glassy $\mathrm{FeCO}_{3}$ recovered from x-ray diffraction experiments using $633 \mathrm{~nm}$ wavelength in order to preserve the samples, using more energetic lower wavelengths resulted in dissociation of the sample and detection of hematite signal.

\section{RESULTS}

All samples are systematically quenched as a glass. Chemical integrity of $\mathrm{FeCO}_{3}$ molten spheres is observed for runs conducted above $40 \mathrm{GPa}$, apart from a marginal fraction at the glass$\mathrm{SiO}_{2}$ interface in one sample showing enrichment of the $P$ transmitting medium in Fe and C. Instead, the lowest $P$ samples, i.e., 11 and $15 \mathrm{GPa}$, have reacted with the $\mathrm{SiO}_{2} P$-transmitting medium. This is shown by SEM imaging (Figure 2) and EMPA analysis on sample 8 (Table $\mathbf{1}$ ). High $P$ carbonate melts are thus 


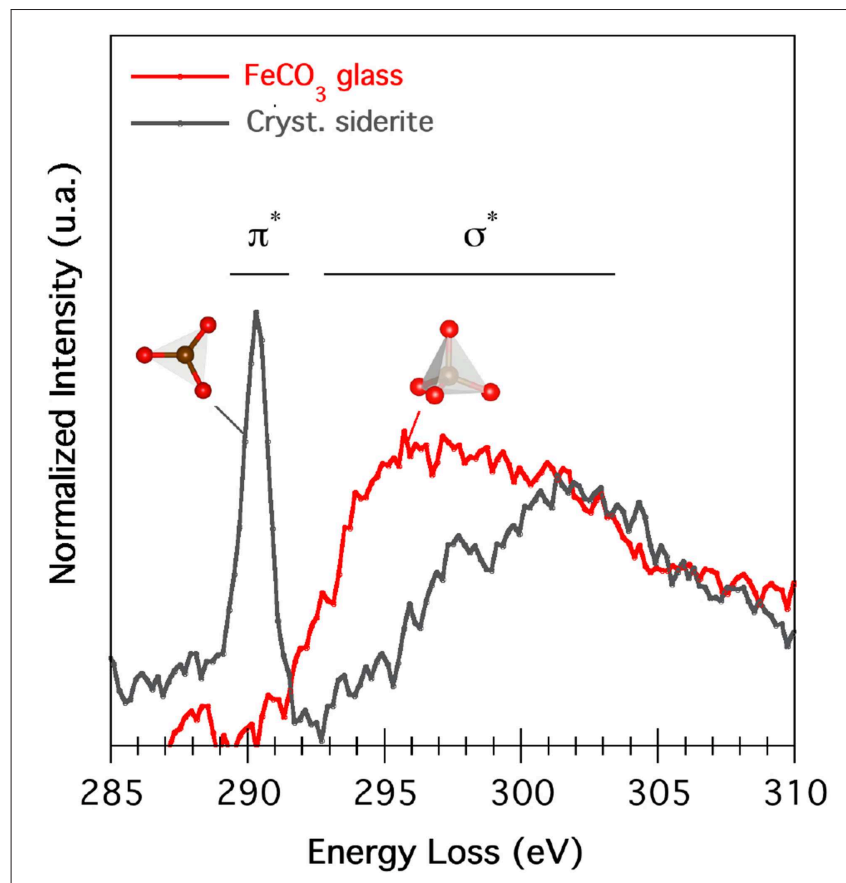

FIGURE 5 | X-ray Raman spectra collected at the carbon K-edge on crystalline siderite and high $P$-quenched $\mathrm{FeCO}_{3}$ glasses at ambient conditions. The disappearance of the $\pi^{*}$ feature, which is solely related to the three-fold coordinated carbon, is a spectroscopic evidence of a full four-fold coordination state in the glassy structure of $\mathrm{FeCO}_{3}$.

much less reactive than low $P$ melts. This might not contradict the observed reactivity of high $P$ crystalline $\mathrm{MgCO}_{3}$ with $\mathrm{SiO}_{2}$ (Seto et al., 2008; Maeda et al., 2017) due to the much longer heating durations (20-240 min against $10 \mathrm{~s}$ heating duration in this work); alternatively, Fe stabilizing effect on high $P$ carbonates could be at stake. We observe no disproportionation of $\mathrm{Fe}$ as was reported in the crystalline state in some studies (Boulard et al., 2011; Cerantola et al., 2017) but not in others (Liu et al., 2015). This might be due to different $P$ - $T$ paths followed, i.e., flash heating here instead of continuous $T$ increase (Boulard et al., 2011; Cerantola et al., 2017).

A striking characteristic of glassy $\mathrm{FeCO}_{3}$ is its strong first sharp diffraction peak (FSDP) that persists in the structure factor up to the highest $P$ investigated (Figure 3A), indicative of a strong medium-range order. This is in stark contrast to silicate glasses that lose their medium-range order with increased $P$ (Sato and Funamori, 2008), but consistent with $a b$ initio calculations on carbon-bearing silicate melts reporting $P$ induced polymerization of carbonate species into dimers and with the silicate network (Ghosh et al., 2017; Solomatova and Asimow, 2019). A second noticeable feature is the decrease of the contribution at $4 \AA^{-1}$ attributed in molten carbonates to the $\mathrm{O}-\mathrm{O}$ bond (Wilding et al., 2016). On radial distribution functions, $g(r)$ (Figure 3B), the C-O contribution is clearly visible at 1.2-1.3 $\AA$ with none or little overlap with the second contribution ( $\mathrm{Fe}-\mathrm{O}$ and $\mathrm{O}-\mathrm{O}$ ) at $\sim 2 \AA$ in the glass, and with some overlap in the melt. No significant structural changes are

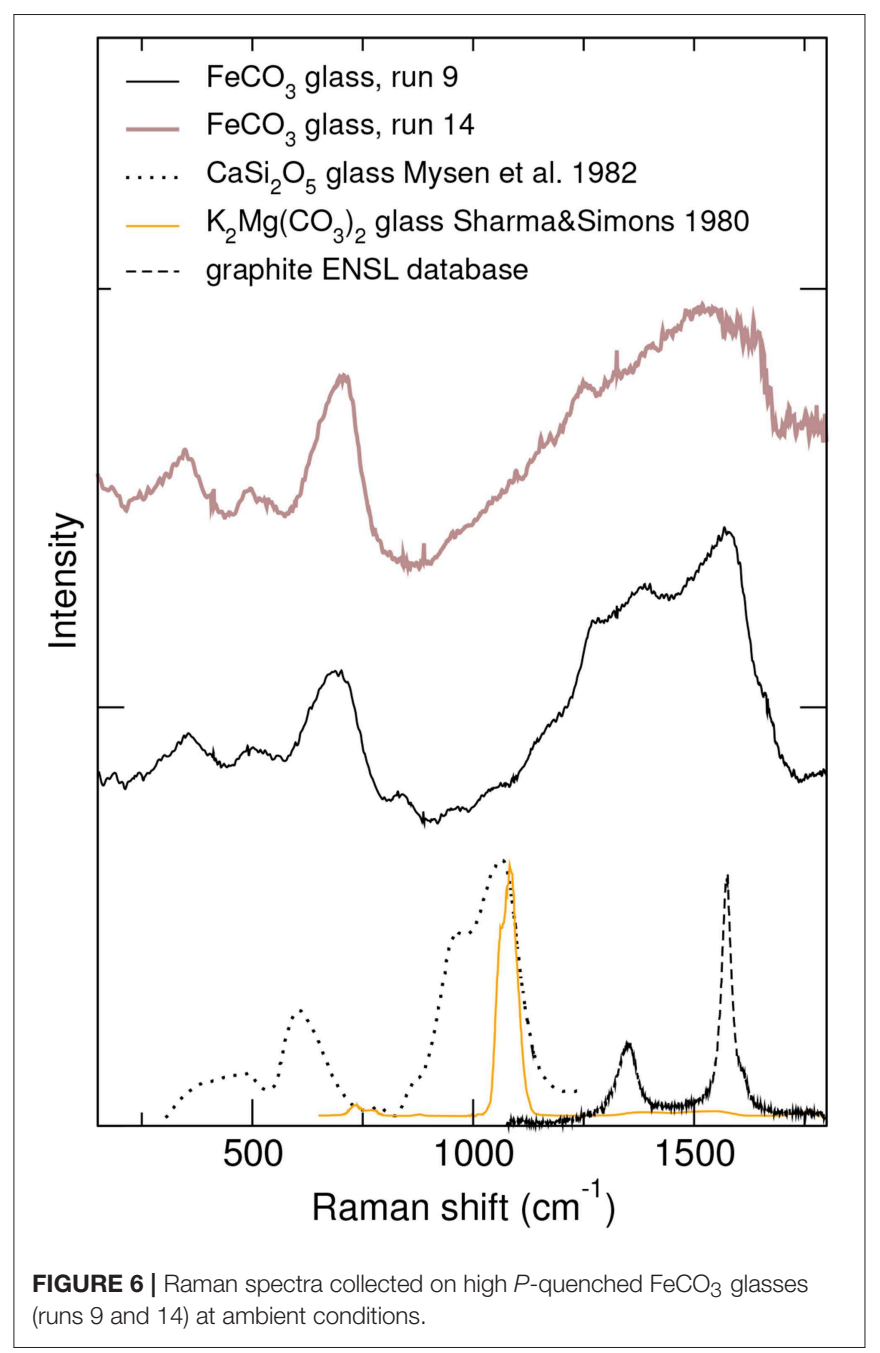

observed between molten and quenched glassy state at $110 \mathrm{GPa}$, apart from a generally lower intensity in the melt due to the high $T$ and consequent higher degree of disorder. For $g(r)$, this weaker intensity translates into broader $\mathrm{C}-\mathrm{O}$ and $\mathrm{Fe}-\mathrm{O} / \mathrm{O}-$ $\mathrm{O}$ contributions in the molten state. For glasses quenched at 11 $\mathrm{GPa}$ and $15 \mathrm{GPa}$, the $\mathrm{x}$-ray structure factor, $S(q)$, is intermediate between that of pure $\mathrm{SiO}_{2}$ glass (Sato and Funamori, 2008) and high- $P \mathrm{FeCO}_{3}$ glasses (Figure 4). SEM image of sample 8 (15 GPa, Figure 2) shows heterogeneities in the quenched glass, which indicates that the $\mathrm{x}$-ray structure factor likely averages at least two types of glass structure and therefore data cannot be interpreted quantitatively.

The x-ray Raman $\mathrm{C}$ K-edge spectrum of quenched $\mathrm{FeCO}_{3}$ glass shows no presence of sp2 3-fold carbon characterized by an intense $\pi^{*}$ peak at $290 \mathrm{eV}$ (Figure 5, $\pi^{*}$ peak). Only the $\sigma^{*}$ peak of tetrahedrally coordinated carbon (Shieh et al., 2013) is visible (Figure 5, $\sigma^{*}$ peak). The totally missing $\pi^{*}$ peak is indicative of a fully sp3 state of carbon atoms in the siderite glass. $P$-induced coordination changes of major cations in silicate melts (e.g., Si, Al) were first reported from the study of glasses quenched from high $P$ (Yarger et al., 1995; Meade, Hemley and Mao, 


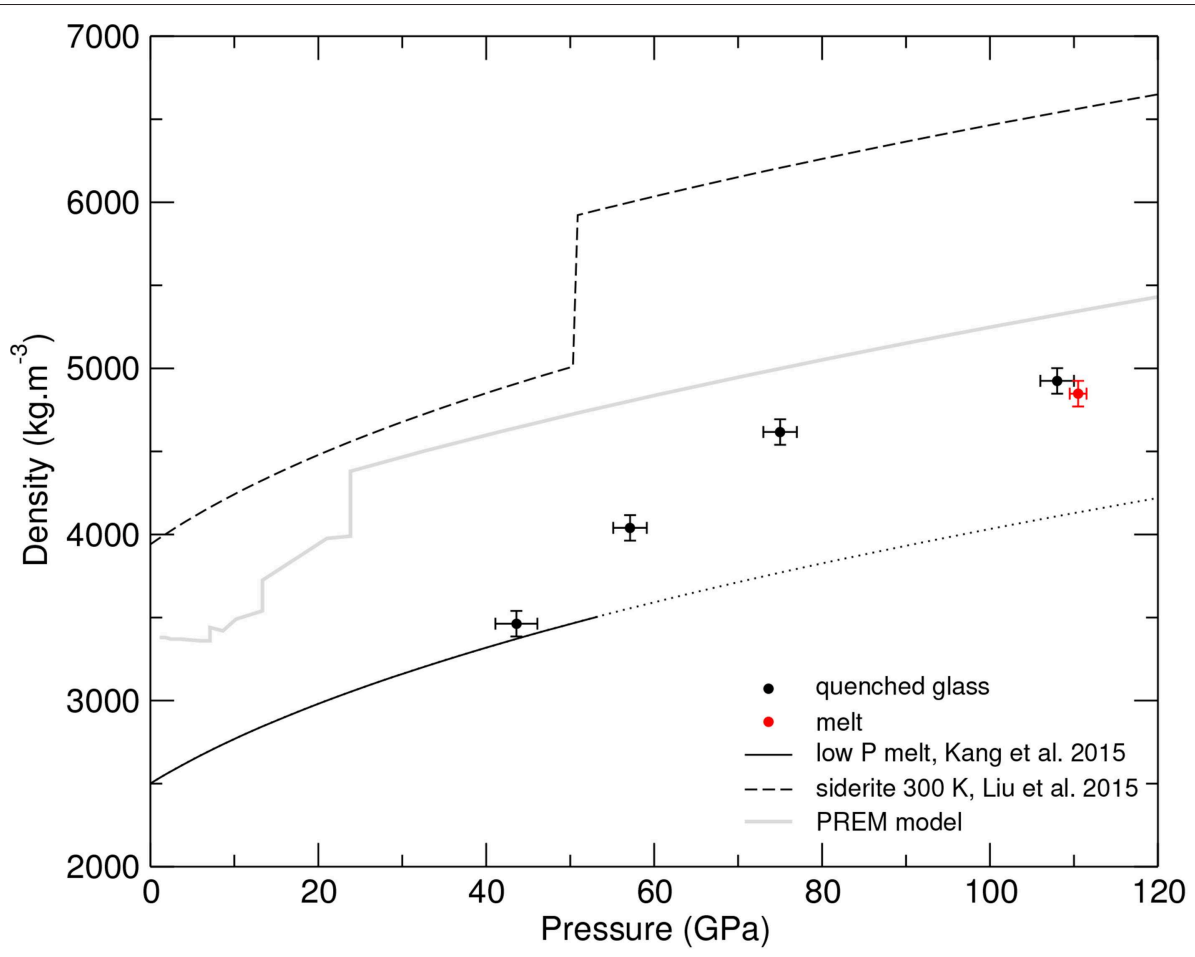

FIGURE 7 | Density evolution of glassy, molten, and cristalline siderite with pressure. Molten low $P$ siderite (plain curve), high $P$ data on glass (black points) and the highest $P$ melt (red point), crystalline equation of state (dashed curve) includes the transition from high spin siderite I to low spin siderite II at 50 GPa (Liu et al., 2015 ).

1992), and later confirmed by in situ studies in the molten phase (Sanloup et al., 2013; Drewitt, 2015). However, the opposite, i.e., coordination change occurring only in the quenched glass, not in the high $P$ melt, have not been reported nor been theoretically predicted. The 3 to 4 -fold transition therefore occurs in molten Fe-carbonates at $P$ less or equal to $51 \mathrm{GPa}$. This transition is preserved upon quenching to the glassy state, and is recoverable at ambient conditions, opening the way to the synthesis of a new class of glassy materials. Two broad bands are observed in the Raman spectra (Figure 6), very different from those of the only two carbonate systems that quench as glasses at room P, $\mathrm{MgCO}_{3}-\mathrm{K}_{2} \mathrm{CO}_{3}$ and $\mathrm{La}(\mathrm{OH})_{3}-\mathrm{Ca}(\mathrm{OH})_{2}-\mathrm{CaCO}_{3}-\mathrm{CaF}_{2} \mathrm{BaSO}_{4}$ (Sharma and Simons, 1979), that are essential dominated by the strong $\mathrm{CO}_{3}^{2-}$ stretching mode at $\sim 1,080 \mathrm{~cm}^{-1}$. Instead, present Raman spectra are reminiscent of those reported for calcium silicate glasses (Figure 6) (Mysen et al., 1982) albeit at higher Raman shift values for the broadest band $\left(1,200-1,600 \mathrm{~cm}^{-1}\right.$ for glassy $\mathrm{FeCO}_{3}$ vs. $850-1,100 \mathrm{~cm}^{-1}$ for calcium silicate glasses).

Density values are reported in Figure 7 along with predictions for lower $P$ melt properties (Kang et al., 2015), $P$-evolution of crystalline siderite, and with the Earth's seismological PREM model (Dziewonski and Anderson, 1981). Density profile below $40 \mathrm{GPa}$ is calculated using $K_{T, 0}$ value of $80.23 \mathrm{GPa}$ (Kang et al., 2015), consistent with that reported for molten calcite (Hudspeth et al., 2018), and density at room $P$ of $2,500 \mathrm{~kg} \cdot \mathrm{m}^{-3}$ by assuming a similar density jump upon melting as for other carbonates for which room $P$ density is known. Comparison with PREM model shows that $\mathrm{Fe}$-carbonate melts are buoyant at all depths. Density contrast between the high $P$ polymerized melt or glass and extrapolated equation of state for low $P$ melt is $15 \%$, i.e., similar to volume collapse reported upon transition from crystalline high spin siderite I to low spin siderite II (Liu et al., 2015). The volume collapse is smoothed out over a $\sim 30 \mathrm{GPa}$ range in the molten state with, as a direct consequence, a steepening of the melting curve from $55 \mathrm{GPa}$ on (Cerantola et al., 2017).

\section{DISCUSSION}

The 3 to 4 -fold transition occurs in molten Fe-carbonates at $P$ less or equal to $51 \mathrm{GPa}$, compared to $50 \mathrm{GPa}$ for crystalline $\mathrm{FeCO}_{3}$ (Liu et al., 2015), $80 \mathrm{GPa}$ for $\mathrm{MgCO}_{3}$ (Oganov et al., 2008; Boulard et al., 2011), and $130 \mathrm{GPa}$ for $\mathrm{CaCO}_{3}$ (Oganov et al., 2006; Arapan et al., 2007). A consequence of the effect of Fe on the 3 -fold $\mathrm{C}$ to 4-fold $\mathrm{C}$ transition $P$ is that crystalline Fe-poor $(\mathrm{Ca}, \mathrm{Mg}, \mathrm{Fe})^{\mathrm{III}} \mathrm{CO}_{3}$ and $\mathrm{Fe}$-enriched $(\mathrm{Ca}, \mathrm{Mg}, \mathrm{Fe})^{\mathrm{IV}} \mathrm{CO}_{3}$ melts could co-exist at depth. In the case of $\mathrm{Si}$ isotopes, fractionation between ${ }^{\mathrm{VI}} \mathrm{Si}$ bridgmanite and ${ }^{\mathrm{IV}} \mathrm{Si}$ olivine structures is theoretically estimated to $\sim-1$ $\%{ }^{28} \mathrm{Si}$ at $2000 \mathrm{~K}$ (Huang et al., 2014). If this effect can be scaled to $\mathrm{C}$ simply using mass difference considerations, then a few $\%{ }^{13} \mathrm{C}$ fractionation is expected, and could potentially explain isotopic differences between calcite inclusions from super-deep diamonds (Kaminsky et al., 2016). This effect might be sufficient to confer a mantle-like signature to deep diamonds grown from slabderived carbonate melts while co-existing tetrahedral crystalline carbonate are expected to get lighter.

Density of non-crystalline $\mathrm{FeCO}_{3}$ remains considerably lower than that of its crystalline counter parts, even at the highest investigated $P$, by $15 \%$. The situation is thus very different from 
that of molten and crystalline silicates which density converge at deep mantle conditions (Petitgirard et al., 2015; Sanloup, 2016), and such difference could be attributed to the very strong medium-range order preserved in tetrahedral high $P$ carbonate melts while it is mostly collapsed by $5 \mathrm{GPa}$ in silicate melts. That high $\mathrm{P} \mathrm{FeCO}_{3}$ melts quench as glasses contrasts with the behavior observed at lower $P$, and suggests an important increase of carbonate melt viscosity consistent with the observation of a very strong medium-range order. It is also opposite to the behavior of molten basalt that systematically quenches as crystalline phases above $11 \mathrm{GPa}$ (Sanloup et al., 2013) and as a glass below. The strongly reduced chemical reactivity of high $P \mathrm{FeCO}_{3}$ melts with silica along with their glass-forming ability suggest that unlike at lower $P$, tetrahedral carbonate melts are not pervasive, which could contribute to the longevity of carbonates in the deep mantle where allowed by oxidizing conditions or slow reduction kinetics (Litasov and Shatskiy, 2018).

\section{AUTHOR CONTRIBUTIONS}

$\mathrm{JH}$ and CS: devised the project; CS: processed $\mathrm{x}$-ray diffraction data and wrote the paper with input from GL and LC; $\mathrm{JH}, \mathrm{CS}, \mathrm{BC}, \mathrm{VA}$, and $\mathrm{ZK}$ : participated in $\mathrm{x}$-ray diffraction data acquisition; JH, GL, LC, CS, and CC: participated

\section{REFERENCES}

Andrault, D., Fiquet, G., Guyot, F., and Hanfland, M. (1998). Pressureinduced landau-type transition in stishovite. Science 282, 720-724. doi: $10.1126 /$ science.282.5389.720

Arapan, S., De Almeida, J. S., and Ahuja, R. (2007). Formation of sp(3) hybridized bonds and stability of $\mathrm{CaCO}_{3}$ at very high pressure. Phys. Rev. Lett. 98:268501. doi: 10.1103/PhysRevLett.98.268501

Boehler, R., Ross, M., and Boercker D. B. (1997). Melting of LiF and $\mathrm{NaCl}$ to 1 Mbar: systematics of ionic solids at extreme conditions Phys. Rev. Lett. 78, 4589-4592. doi: 10.1103/PhysRevLett.7 8.4589

Boulard, E., Gloter, A., Corgne, A., Antonangeli, D., Auzende, A.-L., Perrillat, J.-P., et al. (2011). New host for carbon in the deep Earth. Proc. Natl Acad. Sci. U.S.A. 108, 5184-5187. doi: 10.1073/pnas.1016934108

Boulard, E., Guyot, F., and Fiquet, G. (2012). The influence on Fe content on Raman spectra and unit cell parameters of magnesite-siderite solid solutions. Phys. Chem. Miner. 39, 239-246. doi: 10.1007/s00269-0110479-3

Boulard, E., Guyot, F., Menguy, N., Corgne, A., Auzende, A.-L., Perrillat, J.-P., et al. (2018). $\mathrm{CO}_{2}$-induced destabilization of pyrite-structured $\mathrm{FeO}_{2} \mathrm{H}_{x}$ in the lower mantle. Natl. Sci. Rev. 5, 870-877. doi: 10.1093/nsr/nwy032

Cerantola, V., Bykova, E., Kupenko, I., Merlini, M., Ismailova, L., McCammon, C., et al. (2017). Stability of iron-bearing carbonates in the deep Earth's interior. Nat. Commun. 8:15960. doi: 10.1038/ncomms15960

C. Meade and R. J. Hemley and H. K. Mao (1992). High-pressure X-ray diffraction of $\mathrm{SiO}_{2}$ glass. Phys. Rev. Lett. 69, 1387-1390.

Desmaele, E., Sator, N., Vuilleumier, R. and Guillot, B. (2019). Atomistic simulations of molten carbonates: thermodynamic and transport properties of the $\mathrm{Li}_{2} \mathrm{CO}_{3}-\mathrm{Na}_{2} \mathrm{CO}_{3}-\mathrm{K}_{2} \mathrm{CO}_{3}$ system. J. Chem. Phys. 150:094504. doi: 10.1063/ 1.5082731

Dobson, D. P., Jones, A. P., Rabe, R., Sekine, T., Kurita, K., Taniguchi, T., et al. (1996). In-situ measurement of viscosity and density of carbonate melts at high pressure. Earth Planet. Sci. Lett. 143, 207-215. doi: 10.1016/0012-821X(96)00139-2 in $\mathrm{x}$-ray Raman data acquisition; JH: collected Raman data.

\section{FUNDING}

The research leading to these results has received funding from the European Community's Seventh Framework Programme (FP7/2007-2013) under grant agreements no. 312284 and 259649 (European Research Council starting grant to CS). Portions of this research were carried out at the light source PETRAIII at DESY, a member of the Helmholtz Association (HGF). The laser heating system on beamline P02.2 is funded by the German BMBF (project number 05K10RFA).

\section{ACKNOWLEDGMENTS}

We acknowledge E. Boulard for providing the starting siderite sample, K. Glazyrin for his help with ex situ diamond-anvil cell laser-heating synthesis in PETRAIII, L. Rémusat at Museum National d'Histoire Naturelle (Paris, France) for gold coating of the recovered samples, the ESRF (Grenoble, France) and PETRAIII (Hamburg, Germany) for provision of synchrotron radiation facilities.

Drewitt, J. W. E., Jahn, S., Sanloup, C., de Grouchy, C., Garbarino, G. and Hennet L. (2015). Development of chemical and topological structure in aluminosilicate liquids and glasses at high pressure. J. Phys.: Cond. Matt. 27:105103. doi: 10. 1088/0953-8984/27/10/105103

Du, X., Wu, M., Tse, J. S., and Pan, Y. (2018). Structures and transport properties of CaCO3 melts under Earth's mantle conditions ACS Earth Space Chem 2, 1-8. doi: 10.1021/acsearthspacechem.7b00100

Dziewonski, A. M. and Anderson, D. L. (1981). Preliminary reference Earth model. Phys. Earth Planet. Int. 25, 297-356.

Eggert, J. H., Weck, G., Loubeyre, P., and Mezouar, M. (2002). Quantitative structure factor and density measurements of high-pressure in diamond anvil cells by x-ray diffraction: Argon and water. Phys. Rev. B 65:174105. doi: 10. 1103/PhysRevB.65.174105

Fischer, R. A., Campbell, A. J., Chidester, B. A., Reaman, D. M., Thompson, E. C., Pigott, J. S., et al. (2018). Equations of state and phase boundary for stishovite and $\mathrm{CaCl}_{2}$-type $\mathrm{SiO}_{2}$. Am. Mineral. 103, 792-802. doi: 10.2138/am-2018-6267

Foley, S. F. (2008). Rejuvenation and erosion of the cratonic lithosphere. Nature Geosci. 1, 503-510. doi: 10.1038/ngeo261

Frost, D., Liebske, C., Langenhorst, F., McCammon, C., Tronnes, R., and Rubie, D. (2004). Experimental evidence for the existence of iron-rich metal in the Earth's lower mantle. Nature 428, 409-412. doi: 10.1038/nature02413

Ghosh, D. B., Bajgain, S. K., Mookherjee, M., and Karki, B. B. (2017). Carbonbearing silicate melt at deep mantle conditions. Sci. Rep. 7:848. doi: 10.1038/ s41598-017-00918-x

Hajdu F. (1972). Revised parameters of the analytic fits for coherent and incoherent scattered X-ray intensities of the first 36 atoms. Acta Cryst. A 28, 250-252.

Hammersley, A. P., Svensson, S. O., Hanfland, M., Fitch, A. N., and Hausermann, D. (1996). Two-dimensional detector software: From real detector to idealised image or two-theta scan. High Press. Res. 14, 235-248. doi: 10.1080/ 08957959608201408

Hosemann, R. and Bagchi, S. N. (1962). Direct Analysis of Diffraction by Matter. Amsterdam: North-Holland.

Huang, F., Wu, Z., Huang, S., and Wu, F. (2014). First-principles calculations of equilibrium silicon isotope fractionation among mantle minerals. Geochim. Cosmochim. Acta 140, 509-520. doi: 10.1016/j.gca.2014.05.035 
Hudspeth, J., Sanloup, C., and Kono, Y. (2018). Properties of molten $\mathrm{CaCO}_{3}$ at high pressure. Geochem. Persp. Let. 7, 27-31. doi: 10.7185/geochemlet.1813

Huotari, S., Sahle, C. J., Henriquet, C., Al-Zein, A., Martel, K., Simonelli, L., et al. (2017). A large-solid-angle X-ray Raman scattering spectrometer at ID20 of the European Synchrotron Radiation Facility. J. Sync. Rad. 24, 521-530. doi: 10. $1107 /$ S1600577516020579

Kaminsky, F. (2012). Mineralogy of the lower mantle: a review of 'super-deep' mineral inclusions in diamond. Earth Sci. Rev. 110, 127-147. doi: 10.1016/j. earscirev.2011.10.005

Kaminsky, F., Matzel, J., Jacobsen, B., Hutcheon, I., and Wirth, R. (2016). Isotopic fractionation of oxygen and carbon in decomposed lower-mantle inclusions in diamond. Mineral. Petrol. 110, 379-385. doi: 10.1007/s00710-015-0401-7

Kang, N., Schmidt, M. W., Poli, S., Franzolin, E., and Connolly, A. D. (2015). Melting of siderite to $20 \mathrm{GPa}$ and thermodynamic properties of $\mathrm{FeCO}_{3}$-melt. Chem. Geol. 400, 34-43. doi: 10.1016/j.chemgeo.2015.02.005

Kono, Y. , Kenney-Benson C., Hummer, D., Ohfuji H. , Park, C., Shen, G., et al. (2014). Ultralow viscosity of carbonate melts at high pressures. Nat. Comm. 5:5091. doi: 10.1038/ncomms6091

Li, Z., Li, J.., Lange, R., Liu, J., and Militzer, B. (2017). Determination of calcium carbonate and sodium carbonate melting curves up to Earth's transition zone pressures with implications for the deep carbon cycle. Earth Planet. Sci. Lett. 457, 395-402. doi: 10.1016/j.epsl.2016.10.027

Litasov, K. D. and Shatskiy, A. (2018). Chap. 2: Carbon-Bearing Magmas in the Earth's Deep Interior. Amsterdam: Elsevier.

Litasov, K. D., Shatskiy, A., Ohtani, E., and Yaxley, G. M. (2013). Solidus of alkaline carbonatite in the deep mantle. Geology 41, 79-82. doi: 10.1130/ G33488.1

Liu, J., Lin, J.-F., and Prakapenka, V. B. (2015). High-pressure orthorhombic ferromagnesite as a potential deep-mantle carbon Carrier. Sci. Rep. 5:7640. doi: $10.1038 /$ srep 07640

Lobanov, S. S., Goncharov, A. F., and Litasov, K. D. (2015). Optical properties of siderite $\left(\mathrm{FeCO}_{3}\right)$ across the spin transition: Crossover to iron-rich carbonates in the lower mantle. Am. Mineral. 100, 1059-1064. doi: 10.2138/am-20 15-5053

Lobanov, S. S., Stevanovic, V., Gavryushkin, P. N., Litasov, K. D., Greenberg, E., Prakapenka, V. B., Oganov, A. R. and Goncharov, Al. F. (2017). Raman spectroscopy and $\mathrm{x}$-ray diffraction of $\mathrm{sp}(3) \mathrm{CaCO}_{3}$ at lower mantle pressures. Phys. Rev. B 96:104101. doi: 10.1103/PhysRevB.96.104101

Maeda, F., Ohtani, E., Kamada, S., Sakamaki, T., Hirao, N., and Ohishi, Y. (2017). Diamond formation in the deep lower mantle: a high-pressure reaction of $\mathrm{MgCO}_{3}$ and $\mathrm{SiO}_{2}$. Sci. Rep. 7:40602. doi: 10.1038/srep40602

Mao, H. K., Xu, J., and Bell, P. M. (1986). Calibration of the ruby pressure gauge to 800 kbar under quasi-hydrostatic conditions. J. Geophys. Res. 91, 4673-4676.

Merlini, M., Cerantola, V., Gatta, G. D., Gemmi, M., Hanfland, M., Kupenko, I., et al. (2017). Dolomite-IV: candidate structure for a carbonate in the Earth's lower mantle. Am. Mineral. 102, 1763-1766. doi: 10.2138/am-2017-6161

Mysen, B. O., Finger, L. W., Virgo, D., and Seifert, F. A. (1982). Curve-fitting of Raman spectra of silicate glasses. Am. Mineral. 67, 686-695.

Nishihara, Y., Nakayama, K., Takahashi, E., Iguchi, T., and i. Funakoshi, K. (2005). $\mathrm{P}-\mathrm{V}-\mathrm{T}$ equation of state of stishovite to the mantle transition zone conditions. Phys. Chem. Min. 31, 660-670. doi: 10.1007/s00269-004-0426-7

Oganov, A., Glass, C., and Ono, S. (2006). High-pressure phases of $\mathrm{CaCO}_{3}$ : crystal structure prediction and experiment. Earth Planet. Sci. Lett. 241, 95-103. doi: 10.1016/j.epsl.2005.10.014

Oganov, A. R., Ono, S., Ma, Y., Glass, C. W., and Garcia, A. (2008). Novel highpressure structures of $\mathrm{MgCO}_{3}, \mathrm{CaCO}_{3}$ and $\mathrm{CO}_{2}$ and their role in Earth's lower mantle. Earth Planet. Sci. Lett. 273, 38-47. doi: 10.1016/j.epsl.200 8.06.005

Petitgirard, S., Malfait, W. J., Sinmyo, R., Kupenko, I., Hennet, L., Harries, D., et al. (2015). Fate of $\mathrm{MgSiO}_{3}$ melts at core-mantle boundary conditions. P. Natl. Acad. Sci. U.S.A. 112, 14186-14190. doi: 10.1073/pnas.1512386112

Sahle, C. J., Mirone, A., Niskanen, J., Inkinen, J., Krisch, M., and Huotari, S. (2015). Planning, performing and analyzing X-ray Raman scattering experiments. J. Sync. Rad. 22, 400-409. doi: 10.1107/S1600577514027581
Sanloup, C. (2016). Density of magmas at depth. Chem. Geol. 429, 51-59. doi: 10. 1016/j.chemgeo.2016.03.002

Sanloup, C. and de Grouchy, C. J. L. (2018). Chap. 5: X-ray Diffraction Structure Measurements. Amsterdam: Elsevier.

Sanloup, C., Drewitt, J. W. E., Konôpková, Z., Dalladay-Simpson, P., Morton, D. M., Rai, N., et al. (2013). Structural change in molten basalt at deep mantle conditions. Nature 503, 104-107. doi: 10.1038/nature12668

Sato, T. and Funamori, N. (2008). Sixfold-coordinated amorphous polymorph of $\mathrm{SiO}_{2}$ under high pressure. Phys. Rev. Lett. 101:255502. doi: 10.1103/ PhysRevLett.101.255502

Seto, Y., Hamane, D., Nagai, T., and Fujino, K. (2008). Fate of carbonates within oceanic plates subducted to the lower mantle, and a possible mechanism of diamond formation. Phys. Chem. Miner. 35, 223-229. doi: 10.1007/s00269-0080215-9

Sharma, S. and Simons, B. (1979). Raman Study of $\mathrm{K}_{2} \mathrm{CO}_{3}-\mathrm{MgCO}_{3}$ Glasses, Vol. 79. Washington, DC: Carnegie Institute, 322-326.

Shieh, S. R., Jarrige, I., Wu, M., Hiraoka, N., Tse, J. S., Mi, Z., et al. (2013). Electronic structure of carbon dioxide under pressure and insights into the molecularto-nonmolecular transition. Proc. Natl. Acad. Sci. U. S. A. 110, 18402-18406. doi: 10.1073/pnas.1305116110

Smith, E. M., Shirey, S. B., Nestola, F., Bullock, E. S., Wang, J., Richardson, S. H., et al. (2016). Large gem diamonds from metallic liquid in earth's deep mantle. Science 354, 1403-1405. doi: 10.1126/science.aal1303

Solomatova, N. V. and Asimow, P. D. (2018). First-principles calculations of highpressure iron-bearing monoclinic dolomite and single-cation carbonates with internally consistent Hubbard U. Phys. Chem. Miner. 45, 293-302. doi: 10.1007/ s00269-017-0918-x

Solomatova, N. V., Caracas, R., and Manning, C. E. (2019). Carbon sequestration during core formation implied by complex carbon polymerization. Nat. Comm. 10:789. doi: 10.1038/s41467-019-08742-9

Stagno, V., Stopponi, V., Kono, Y., Manning, C. E. and Tetsuo, I. (2018). Experimental determination of the viscosity of $\mathrm{Na}_{2} \mathrm{CO}_{3}$ melt between 1.7 and 4.6 GPa at 1200-1700 degrees C: implications for the rheology of carbonatite magmas in the Earth's upper mantle. Chem. Geol. 501,19-25. doi: 10.1016/j. chemgeo.2018.09.036

Vuilleumier, R., Seitsonen, A., Sator, N., and Guillot, B. (2014). Structure, equation of state and transport properties of molten calcium carbonate $\left(\mathrm{CaCO}_{3}\right)$ by atomistic simulations. Geochim. Cosmchim. Acta 141, 547-566. doi: 10.1016 j.gca.2014.06.037

Weis, C., Sternemann, C., Cerantola, V., Sahle, C. J., Spiekermann, G., Harder, M., et al. (2017). Pressure driven spin transition in siderite and magnesiosiderite single crystals. Sci. Rep. 7:16526. doi: 10.1038/s41598-017-16733-3

Wilding, M. C., Wilson, M., Alderman, O. L. G., Benmore, C., Weber, J. K. R., Parise, J. B., et al. (2016). Low-dimensional network formation in molten sodium carbonate. Sci. Reports 6:24415. doi: 10.1038/sre p24415

Yarger, J. L., Smith, K. H., Nieman, R. A., Diefenbacher, J., Wolf, G. H., Poe, B. T., McMillan, P. F. (1995). Al coordination changes in high-pressure aluminosilicate liquids. Science 270, 1964-1967.

Zhang, Z., and Liu, Z. (2015). High pressure equation of state for molten $\mathrm{CaCO}_{3}$ from first principles simulations. Chin. J. Geochem. 34, 13-20. doi: 10.1007/ s11631-015-0036-8

Conflict of Interest Statement: The authors declare that the research was conducted in the absence of any commercial or financial relationships that could be construed as a potential conflict of interest.

Copyright (c) 2019 Sanloup, Hudspeth, Afonina, Cochain, Konôpková, Lelong, Cormier and Cavallari. This is an open-access article distributed under the terms of the Creative Commons Attribution License (CC BY). The use, distribution or reproduction in other forums is permitted, provided the original author(s) and the copyright owner(s) are credited and that the original publication in this journal is cited, in accordance with accepted academic practice. No use, distribution or reproduction is permitted which does not comply with these terms. 